\title{
Structural and Electrical Properties of Copper Sulfide (CuS) Thin Films doped with Mercury and Nickel impurities.
}

\author{
J. C. Osuwa ${ }^{1}$ and E. C. Mgbaja ${ }^{2}$ \\ Department of Physics, Michael Okpara University of Agriculture, Umudike, PMB 7267, Abia State, Nigeria.
}

\begin{abstract}
Chemical bath deposited copper sulfide (CuS) thin films were doped with varying concentrations of mercury ( $\mathrm{Hg}$ ) and nickel (Ni) impurities (0.01-0.03M) on glass substrates at room temperature of $27^{\circ} \mathrm{C}$. X-ray diffraction (XRD) and four-point probe techniques were used to analyze the structural and electrical properties as well as the thickness of the doped $\mathrm{CuS}$ thin films. The XRD results reveal that the films have mono-crystallite structure with broadening of the diffraction peak by both impurities. Values of the Bragg's angle obtained were $2 \theta=29.28^{\circ}$ for the diffraction peak of Ni impurities and $2 \theta=27.86^{\circ}$ for the diffraction peak of $\mathrm{Hg}$ impurities as compared to un-doped $\mathrm{CuS}$ thin films whose diffraction peak occurred at $2 \theta=23.71^{\circ}$. The electrical resistivity of the films dropped from about $2000 \Omega$-cm for the un-doped CuS thin film to zero value for $0.01 \mathrm{M}$ of $\mathrm{Ni}$ impurities and then reversed from negative value back to zero for Ni impurities of equal to or greater than $0.02 \mathrm{M}$ concentration. For $\mathrm{Hg}$ impurities, the electrical resistivity first rose to 6,600 $\Omega$-cm for 0.01M impurity, then dropped symmetrically back to $2000 \Omega$-cm for 0.02M impurity and gradually decreased with higher concentrations of Hg impurities. Corresponding variations in electrical conductivity, dielectric constants and film thickness with impurity concentrations are also reported in this paper.
\end{abstract}

Keywords: XRD, four-point probe, $\mathrm{Hg}$ and Ni impurities, diffraction peak, Bragg's angle.

\section{Introduction}

Copper sulfide is a p-type semiconducting material which belongs to I-VI compound semiconductor metals. Chalcogenide thin films of copper sulfide have received particular attention since the discovery of the $\mathrm{CdS} / \mathrm{CuS}$ hetrojunction solar cell in 1954 [1]. Other applications of $\mathrm{CuS}$ thin films include laminated glazing, photo-thermal conversion, electro-conductive electrode, microwave shielding and solar control coatings [2-6]. It is also used in photo-detectors and photovoltaic applications.

Electrical resistivity and conductivity of $\mathrm{CuS}$ thin films are dependent on various film and growth parameters including film composition, film thickness and impurity concentrations among others [7-11]. In this paper, the effects of molar concentrations of $\mathrm{Hg}$ and $\mathrm{Ni}$ on the electrical resistivity, conductivity and dielectric constants of $\mathrm{CuS}$ thin films prepared by $\mathrm{CBD}$ technique have been investigated. Also presented are the effects of the impurity concentrations on the film structure and thickness.

\section{Experimental Details}

Analytical grade reagents used for the CuS thin film deposition include copper sulphate (CuSO4) as the precursor for copper ions, tri ethanol amine (TEA) as a complexing agent, thiourea (CS(NH2)2) as the precursor for sulfur ions and ammonia as the $\mathrm{pH}$ adjuster. Glass substrates were degreased with hydrochloric acid $(\mathrm{HCl})$ for 48 hours, washed in cold water with detergent, rinsed with distilled water and dried in air for some minutes.

Then $7.5 \mathrm{ml}$ of $0.755 \mathrm{M}$ of already prepared tri ethanol amine was measured out with clinical syringe and poured into $100 \mathrm{ml}$ beaker that already contained $15 \mathrm{ml}$ of $0.1 \mathrm{M} \mathrm{CuSO} 4$ solution. The mixture was stirred, after which $30 \mathrm{ml}$ of thiourea solution was measured and added to the beaker with constant stirring. Finally, 4.5 $\mathrm{ml}$ of ammonia (NH3) was added to the mixture.

Cleansed glass substrates were then inserted vertically into the reaction bath with the help of a synthetic foam/holder, which also partly covered the top of the beaker containing the bath. The bath was left undisturbed for 3 to 5 hours at a constant room temperature of $27{ }^{\circ} \mathrm{C}$. This was followed with varying concentrations of mercury chloride and nickel chloride, the sources of nickel and mercury impurity ions, which were mixed separately with copper sulphate in different beakers and stirred thoroughly. Other reagents were orderly added as in the case of copper sulfide deposition. The mixtures were again thoroughly stirred and cleansed glass substrates were inserted and left undisturbed for hours for the deposition of the doped thin films. After deposition, the substrates were taken out, rinsed in distilled water, dried in air and stored for analyses.

\section{Results and Discussion}

The analyses of the $\mathrm{CuS}$ thin films were performed using X'PERT PRO diffractometer with $\mathrm{CuK}_{a}$ radiation of wavelength $1.54068 \mathrm{~A}$ in the $2 \Theta$ scanning mode to record the XRD data and Vander Pauw Four- 
Point probe machine for the film thickness and resistivity measurements. Fig. 1 ( $a$ and b) show the increase in film thickness with impurity concentrations for both $\mathrm{Hg}$ and $\mathrm{Ni}$ impurities.
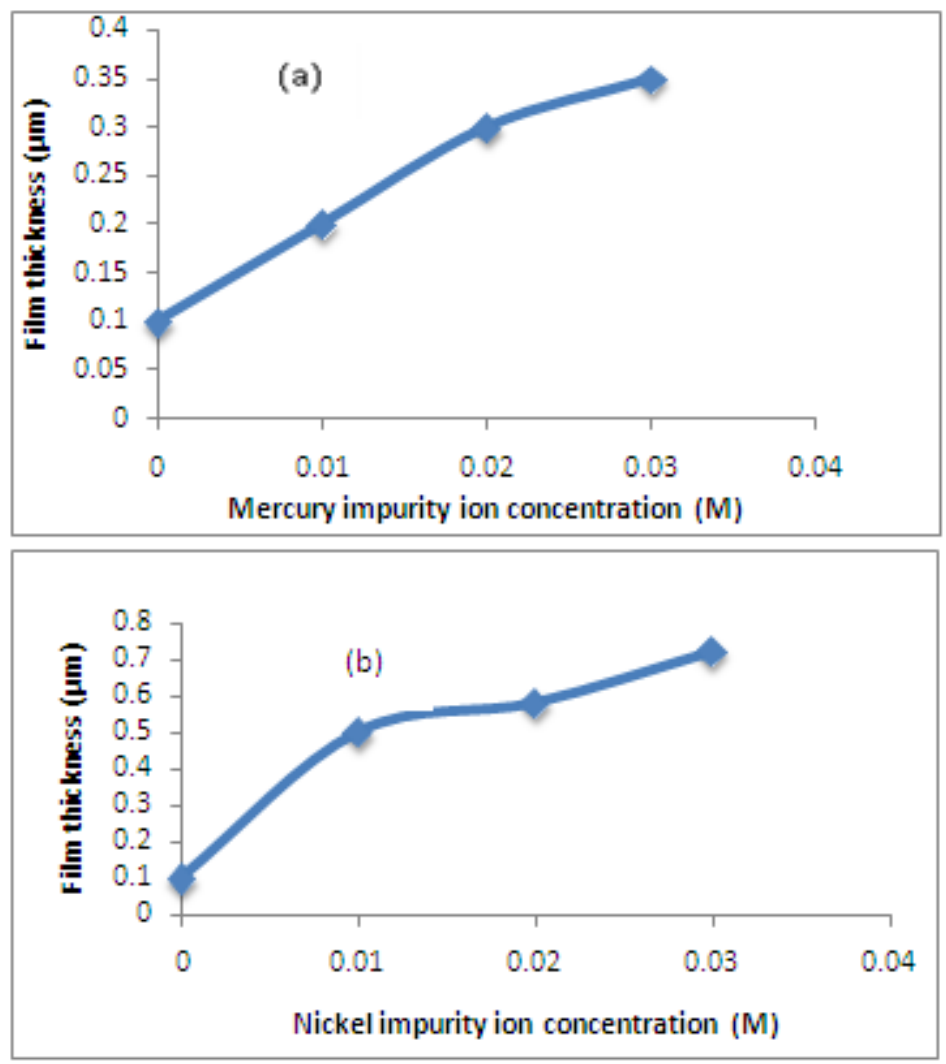

Fig.1: Variation in film thickness of CuS thin films with (a) Mercury impurities (b) Nickel impurities
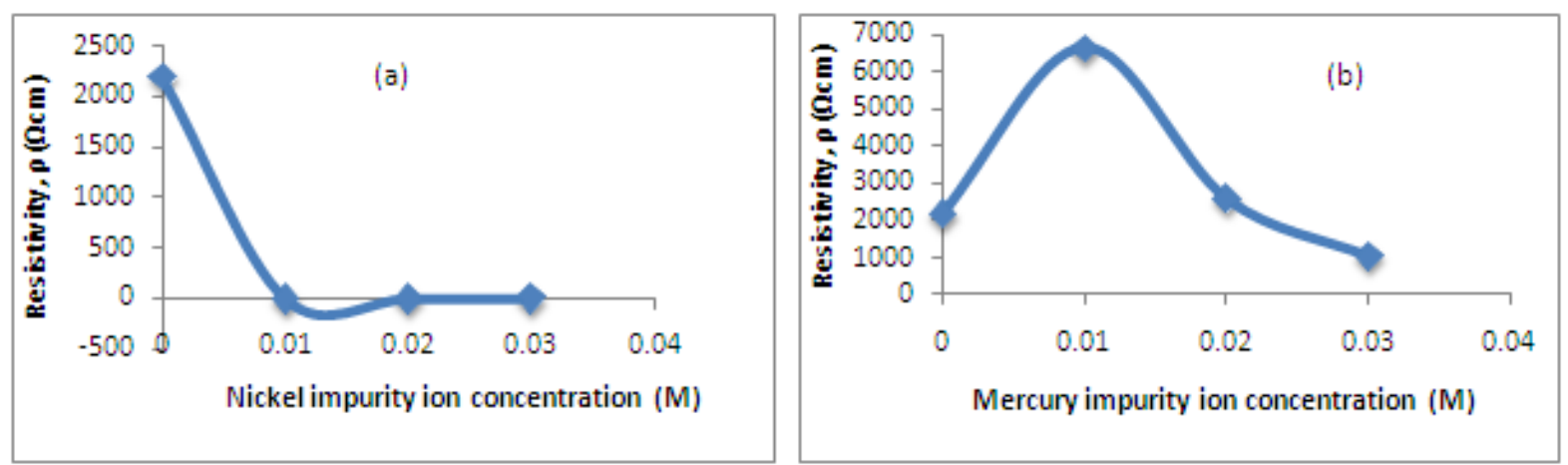

Fig.2: Variation in resistivity of CuS thin films with (a) Nickel impurities (b) Mercury impurities.
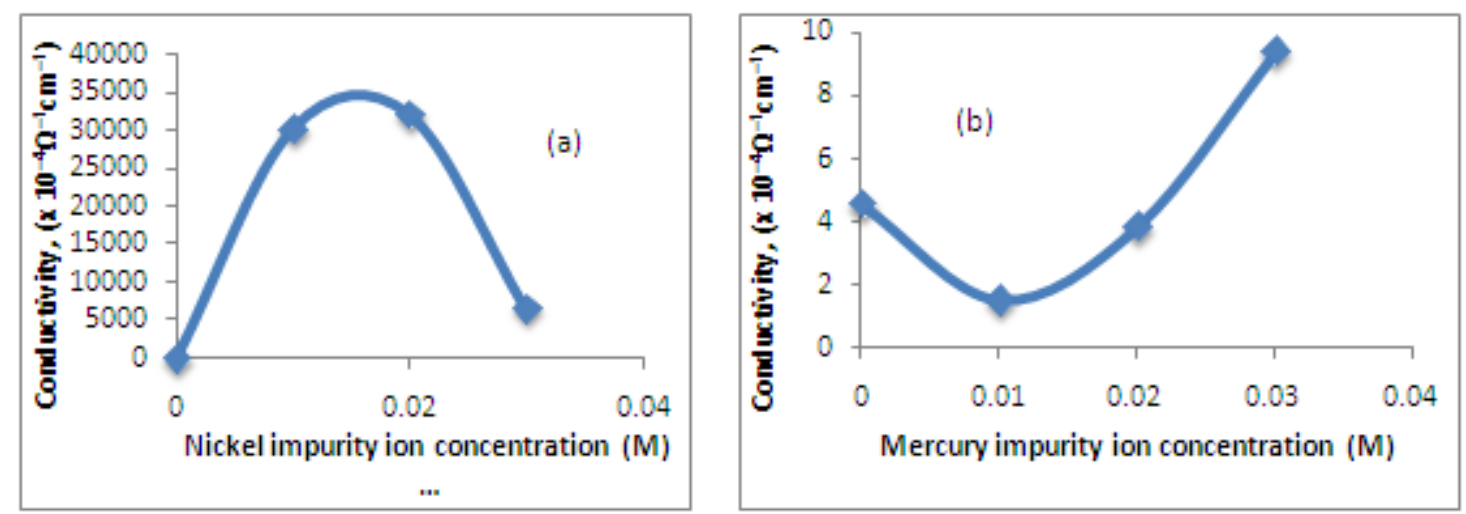

Fig. 3: Variation in conductivity of CuS thin films for (a) Nickel impurities (b) Mercury impurities. 

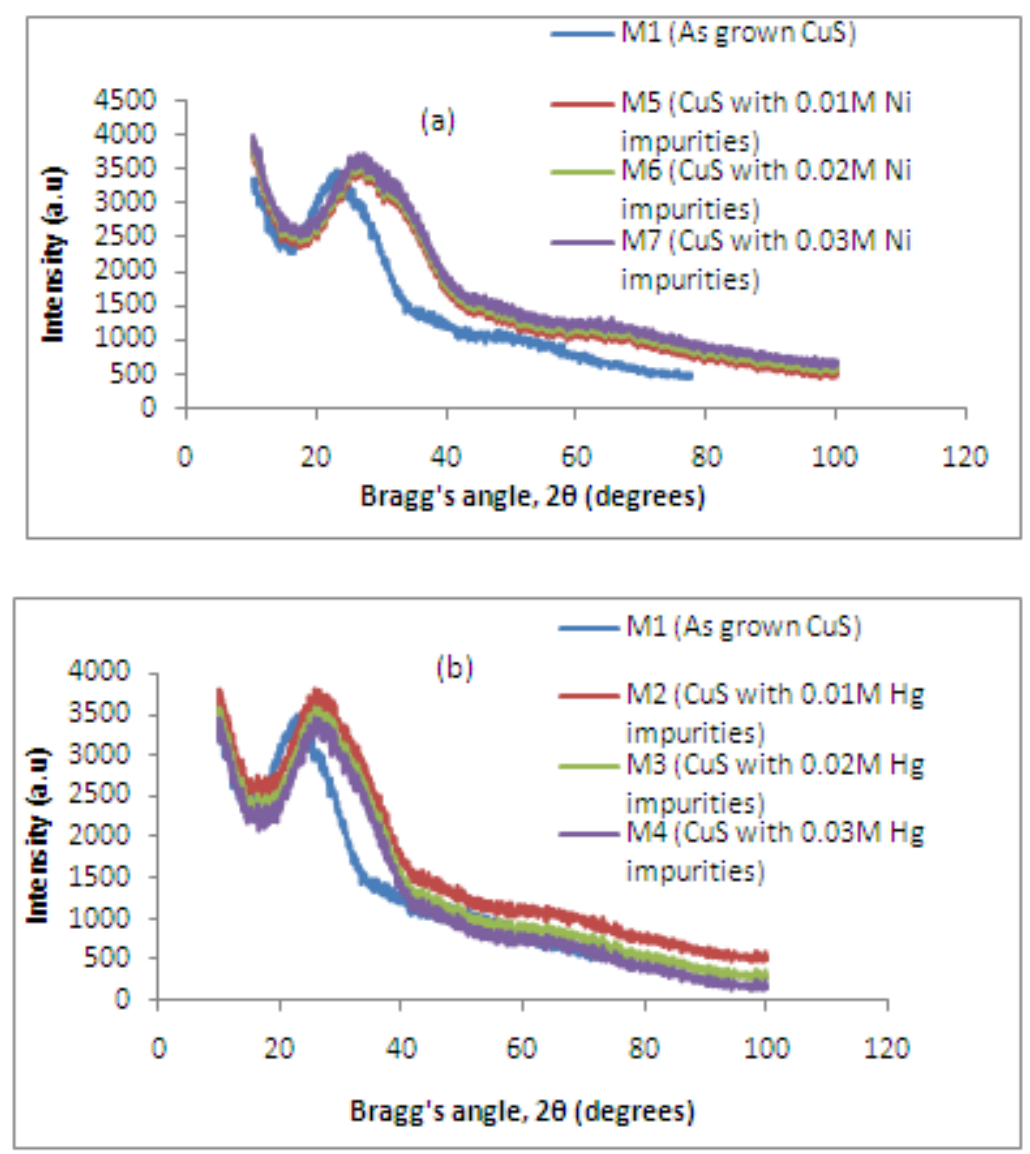

Fig. 4: XRD patterns for CuS thin films for (a) Nickel impurities (b) Mercury impurities.
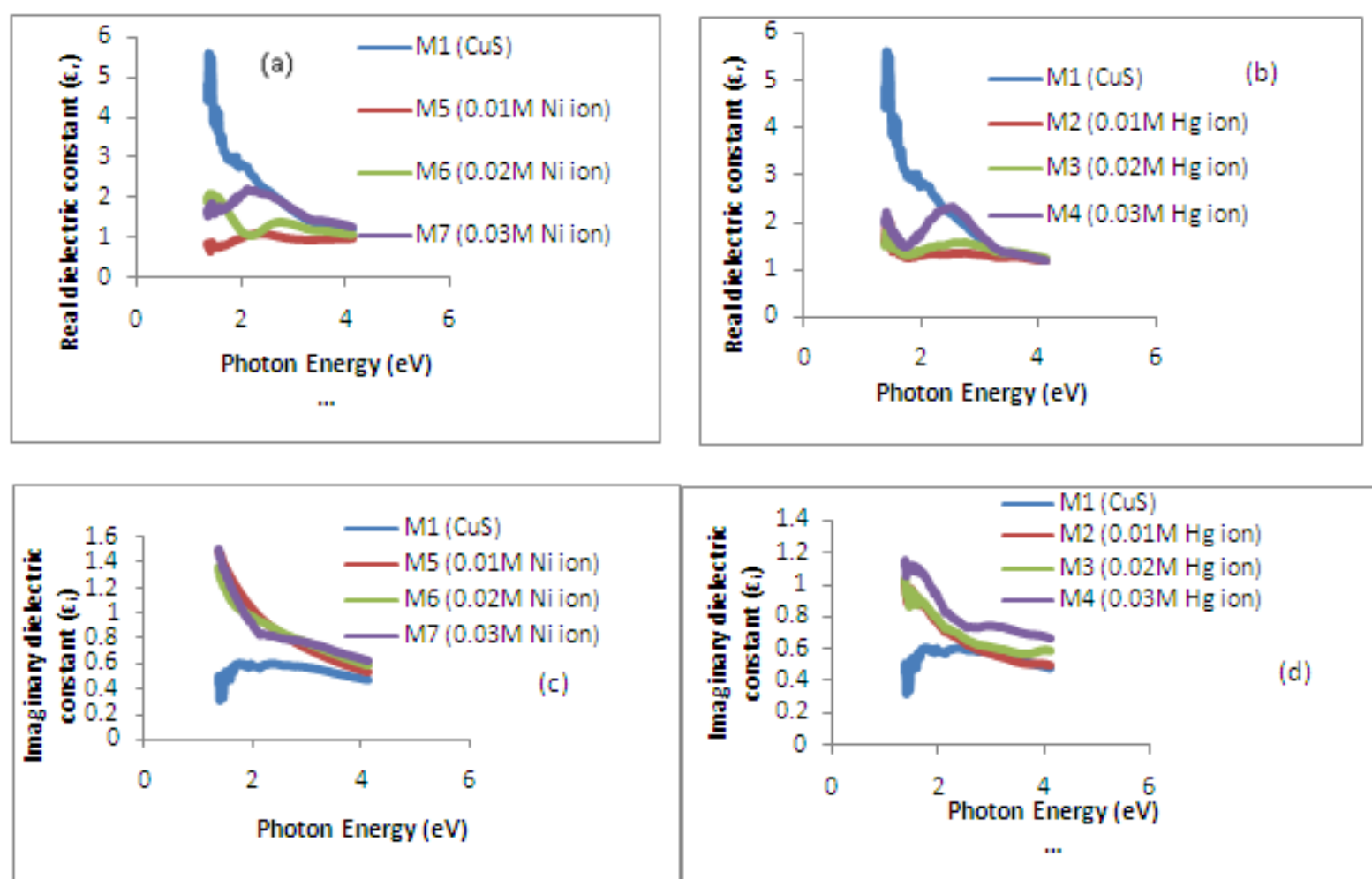

(d)

Fig. 5: Real and Imaginary dielectric constants for $\mathrm{CuS}$ thin films with (a and c) Nickel impurities (b and d) Mercury impurities. 
Figures 2 and 3 respectively, show the variations in the resistivity and conductivity of the doped $\mathrm{CuS}$ thin films. In Fig. 2(a), 0.01M of Ni impurities decreased the resistivity from un-doped value of $2000 \Omega$-cm to zero and maintained zero value for Ni concentrations equal to or greater than 0.02M, while in Fig. 2(b), 0.01M of $\mathrm{Hg}$ impurity first increased the resistivity of the film from $2000 \Omega-\mathrm{cm}$ to about $6.600 \Omega$-cm, then dropped symmetrically back to $2000 \Omega$-cm for $0.02 \mathrm{M} \mathrm{Hg}$ concentration and decreased further for higher concentrations. The corresponding conductivity values are as shown In Fig.3.

Figures 4 ( $\mathrm{a}$ and $\mathrm{b}$ ) show the XRD patterns for Ni and $\mathrm{Hg}$ impurities indicating peak broadening for both impurity concentrations. The figures also show that the peak broadening increases slightly with increase in $\mathrm{Ni}$ impurity concentration at $2 \theta=29.28^{\circ}$ and decreases with increase in $\mathrm{Hg}$ impurity concentrations at $2 \theta=$ $27.86^{\circ}$ while the diffraction peak for the un-doped $\mathrm{CuS}$ thin film remains at $2 \theta=23.71^{\circ}$. The peak broadening is indicative of formation of smaller crystallite sizes.

Finally, Fig. 5(a-d) show the effects of $\mathrm{Ni}$ and $\mathrm{Hg}$ impurities on the real and imaginary dielectric constants of the thin films of copper sulfide.

\section{Conclusion}

The deposition and analyses of structural and electrical properties of copper sulfide (CuS) thin films doped with varying concentrations of mercury and nickel impurity ions have been carried out successfully. XRD results reveal mono-crystallite structures for both impurities with diffraction peak broadening. The film thickness also increased with impurity concentration for both impurities. The resistivity of the CuS thin films decreased to zero for $0.01 \mathrm{M} \mathrm{Ni}$ impurity from $2000 \Omega$-cm for the un-doped thin film, while $\mathrm{Hg}$ impurities produced first an increase to $6,600 \Omega-\mathrm{cm}$, then a decrease in the resistivity of the thin films with increase in impurity concentration. The effects of the impurities on the electrical conductivity and dielectric constants of the thin films are as reported in this paper.

\section{References}

[1]. Osuwa J. C and Mgbaja E. C, (2013) Effects of mercury and nickel impurities on optical properties of copper sulfide (CuS) thin flms deposited by chemical birth technique. IOSR Journal Of Environmental Science. Vol. 5.Issue 2, pp. 27-31

[2]. Grozdanov I and Najdoski M, (1995) Optical and Electrical properties of copper sulphide films of variable composition. J. Solid State Chem. 114469.

[3]. Suarez R and Nair P. K, (1996) Co-Deposition of PbS-CuS thin films by chemical Technique. J. Solid State Chem. 123296

[4]. Ottih I. E and Ekpunobi A. J, (2010) X-ray and optical characterization chemical bath Deposited Cadmium Nickel Sulphide CdNiS thin films. Journal of Basic Physical Research. Vol, I p 17-23,

[5]. Nascu C, Pop I, Ionescu V, Indrea E and Bratu I (1997) Spray pyrolysis of Cu thin films. Mater. Lett. 3273

[6]. Osuwa, J. C and Onyejiuwa, G. I, (2013) Structural and Electrical properties of annealed Nickel Oxide(NiO) thin films prepared by chemical bath deposition. Journal ot Ovonic Research. 9(1): 9-15.

[7]. Ezenwa, I. A (20113) Effects of deposition time on the absorbance of chemical bath deposited CuS thin films. Research Journal of engineering sciences. 2(1): 1-4.

[8]. Huda Abdullah, Norhabibi Saada and Sahbuddin Shaari (2012) Effect of deposition time on ZnS thin film properties by chemical bath deposition (CBD) technique. World Applied Sciences Journal. 9(8): 1087-1091.

[9]. Patil, S. G and Tredgold, R. H (1971) Electrical and photo-conductive properties on SnS 2 Crystals. J. Phys. D: Appl. Phys. 4 718.

[10]. Panta, G. P, Subedi D. P (2012) Electrical characterization of Aluminum (Al) Thin Films Measured By Using Four-Point Probe method. Kathmandu University journal of science, Engineering and technology. Vol. 8, pp. 31-36.

[11]. Sartale, S. D and Lokhande, C. D (2001) Preparation and characterization of Nickel Sulphide Thin Films using Successive Ionic Layer Adsorption and Reaction (SILAR). Material Chem. and Phys. 72(8): 100-104. 